\title{
The association between suicide risk and self- esteem in Japanese university students with major depressive episodes of major depressive disorder
}

This article was published in the following Dove Press journal:

Neuropsychiatric Disease and Treatment

15 May 2014

Number of times this article has been viewed

\author{
Nobuyuki Mitsui' \\ Satoshi Asakura ${ }^{1,2}$ \\ Yusuke Shimizu' \\ Yutaka Fujii' \\ Atsuhito Toyomaki' \\ Yuki Kako' \\ Teruaki Tanaka' \\ Nobuki Kitagawa ${ }^{3}$ \\ Takeshi Inoue' \\ Ichiro Kusumi' \\ 'Department of Psychiatry, Hokkaido \\ University Graduate School of \\ Medicine, ${ }^{2}$ Health care center of \\ Hokkaido University, Kita-ku, Sapporo, \\ ${ }^{3}$ Department of Clinical Social \\ Work, Health Sciences University \\ of Hokkaido School of Nursing and \\ Social Services, Tobetsu, Ishikari, Japan
}

Correspondence: Nobuyuki Mitsui Department of Psychiatry, Hokkaido University Graduate School of Medicine, North 15, West 7, Kita-ku, Sapporo, 060-8638, Japan

$\mathrm{Tel}+8 \mid$ I I 716 |l6।

Fax+8I II 706508

Email nmitsui@med.hokudai.ac.jp
Background: The suicide risk among young adults is related to multiple factors; therefore, it is difficult to predict and prevent suicidal behavior.

Aim: We conducted the present study to reveal the most important factors relating to suicidal ideation in Japanese university students with major depressive episodes (MDEs) of major depressive disorder (MDD).

Methods: The subjects were 30 Japanese university students who had MDEs of MDD, and were aged between 18 and 26 years old. They were divided into two groups - without suicide risk group ( $n=15)$, and with suicide risk group $(n=15)$ - based on the results of the Mini-International Neuropsychiatric Interview. Additionally, healthy controls were recruited from the same population ( $\mathrm{n}=15$ ). All subjects completed the self-assessment scales including the Beck Depression Inventory 2nd edition (BDI-II), the Beck Hopelessness Scale (BHS), Rosenberg's Self-Esteem Scale (RSES), and SF-36v2 ${ }^{\mathrm{TM}}$ (The Medical Outcomes Study 36-item short-form health survey version 2), and they were all administered a battery of neuropsychological tests.

Results: The RSES score of the suicide risk group was significantly lower than the RSES score of the without suicide risk group, whereas the BDI-II score and the BHS score were not significantly different between the two groups. The mean social functioning score on the SF-36v2 of the with suicide risk group was significantly lower than that of the without suicide risk group.

Conclusion: The individual's self-esteem and social functioning may play an important role in suicide risk among young adults with MDEs of MDD.

Keywords: suicide risk, self-esteem, quality of life, young adults

\section{Introduction}

Youth suicide is one of the major concerns in present-day Japan, as it has been the leading cause of death among young adults in Japan. ${ }^{1}$ Suicidal behaviors are thought to be a multifactorial phenomenon; ${ }^{2,3}$ therefore, it is very difficult to predict and prevent the occurrence of suicidal behavior., ${ }^{4,5}$ In previous studies, many factors correlated with suicidal behavior have been reported. ${ }^{2,6,7}$ The factors correlated with suicide are categorized as state-dependent or trait-dependent factors. Psychiatric disorders, physical disorders, and psychosocial crises can be categorized as state-dependent factors. Genetic loadings, personality characteristics, and early traumatic life events are categorized as trait-dependent factors. ${ }^{2}$ Major depressive episodes (MDEs) are one of the most important state-dependent factors in major depressive disorder (MDD) because patients with an affective disorder generally commit suicide during an MDE. ${ }^{7,8}$ In previous studies, $47 \%$ to $69 \%$ patients with MDD had suicidal ideation during an MDE. ${ }^{7}$ 
Although an MDE is significantly correlated with suicide risk in MDD, the prediction of suicide remains difficult. Because the mean rates of suicide in MDD patients are reported to be approximately $10 \%$, the majority of MDD patients do not commit suicide. ${ }^{9}$ Therefore, correlated factors with suicide risk other than MDEs, such as hopelessness, ${ }^{10}$ cognitive rigidity, ${ }^{11-14}$ low self-esteem, ${ }^{15-23}$ and low quality of life, ${ }^{24,25}$ could play additional significant roles in MDD. In addition, personality traits including neuroticism, introversion, and harm avoidance are risk factors for suicide. ${ }^{26,27}$ In an earlier study, we reported the relationship between suicidality and personality in Japanese undergraduate students using Temperament and Character Inventory (TCI) ${ }^{28}$

In the present study, we focused on several risk factors for suicide, such as hopelessness, cognitive rigidity, low self-esteem, and low quality of life. Concerning cognitive rigidity, few previous studies have investigated the cognitive function of young adults with suicide risk. ${ }^{29}$ Moreover, the relationship between cognitive rigidity and other contributory factors of suicide risk have not been previously examined in young adults with MDE of MDD. This study was conducted in unmedicated undergraduate student populations to reduce the bias of the effects of drugs on cognition. We examined psychological, cognitive, and social factors to reveal the effects of these factors on suicide risk in unmedicated Japanese young adult populations with MDEs of MDD.

\section{Methods}

\section{Participants and procedure}

Participants were recruited from the Hokkaido University Health Care Center consecutively between May 2011 and July 2012. Psychiatrists at the Health Care Center evaluated 34 unmedicated students aged between 18 and 26 years old, who had depressive symptoms. Then, a Mini-International Neuropsychiatric Interview (MINI) ${ }^{30}$ was conducted and the DSM-IV-TR (Diagnostic and Statistical Manual of Mental Disorders, 4th Edition, Text Revision) diagnoses for these students were confirmed. Three students were excluded due to the following diagnoses: panic disorder without an MDE in one student, bipolar disorder in one student, and dysthymia without an MDE in another student. Another student was excluded because of an incomplete self-report questionnaire. The 30 remaining students with MDE of MDD were included as subjects in this study. The section on "suicidality" in MINI was used as the assessment of suicidal ideation and suicidal behavior. Subjects who had more than five points in the "suicidality" category, which is the threshold of moderate suicide risk, were defined as the suicide risk group. As a result, 15 out of the 30 subjects were defined as the suicide risk group.

Healthy controls were recruited from among Hokkaido University undergraduate students who visited the Hokkaido University Health Care Center for routine medical examinations. Students aged 18 to 26 years old were included in this study. Twenty-three students participated in the study, but three subjects were excluded by the MINI screen, which was a self-report questionnaire for the screening of several psychiatric illnesses. Moreover, five subjects were excluded for incomplete self-report questionnaires. Fifteen healthy controls were included in the analyses.

Written informed consent was obtained from all subjects prior to participation in the study. This study was approved by the Institutional Review Board of Hokkaido University Hospital and was conducted in accordance with the ethical standards established in the 1964 Declaration of Helsinki.

\section{Measurements}

Mini-International Neuropsychiatric Interview (MINI) The MINI was used to diagnose MDE and confirm the psychiatric comorbidities. The MINI, which is a short, structured interview with high validity and reliability, was developed to diagnose 17 psychiatric disorders according to the DSMIV-TR in adults aged 18 years or older. ${ }^{30}$ Although the MINI should not be a substitute for a psychiatric clinical interview, validation studies confirmed the validity of this instrument as a reliable tool in psychiatric diagnosis for the DSM-IV-TR. ${ }^{30}$ The MINI was translated into Japanese in a previous study using the standard procedure of back translation. The Japanese version of the MINI was validated using the Structured Clinical Interview for the Diagnostic and Statistical Manual of Mental Disorders, 3rd Edition, Text Revision in a previous study. ${ }^{31}$ The section for suicidality in the MINI classifies subjects into four groups: no suicide risk, low suicide risk, moderate suicide risk, and high suicide risk. For the present analysis, subjects with moderate suicide risk or high suicide risk based on MINI suicidality category scoring $(\geq 6)$ were classified into the MDEs with suicide risk group.

\section{Self-report methods}

The severity of depression was assessed using the Beck Depression Inventory 2nd edition (BDI-II), which is a 21-item self-report questionnaire (range 0-60). ${ }^{32}$ The BDI-II has been determined to represent a reliable and valid measure of depression; it was validated for college students aged 18 years or older. ${ }^{33}$ The Japanese version of the BDI-II was also validated. ${ }^{34}$ Negative expectancies and hopelessness were assessed using 
the Beck Hopelessness Scale (BHS). The BHS is a self-report measure that assesses negative expectancies about the future based on 20 true-false statements, and that has been validated for adults aged 18 years or older. ${ }^{35}$ Patients with a score of nine or higher were reported to be eleven times more likely to die by suicide than those with lower scores. ${ }^{36}$ The Japanese version of the BHS, the validity of which has been confirmed, was used. ${ }^{37}$ Self-esteem was assessed using the Rosenberg's Self-Esteem Scale (RSES), ${ }^{38}$ which has been validated for undergraduate students. ${ }^{39}$ This scale is widely used for measuring a person's global self-esteem. The Japanese version of the RSES was used. ${ }^{40}$

Health-related quality of life was measured using the Medical Outcomes Study 36-item short-form health survey (SF-36v2 ${ }^{\mathrm{TM}}$; QualityMetric Incorporated, Lincoln, RI, USA). This scale measures the following eight health concepts: limitations in physical activities because of health problems (physical functioning); limitations in social activities because of physical or emotional problems (social functioning); limitations in usual role activities because of physical health problems (role physical); bodily pain (BP); general mental health; limitations in usual role activities because of emotional problems (role emotional, RE); vitality (VT); and general health perception (GH). ${ }^{41}$ A self-report version for measuring health status and outcomes from the patient's perspective was used. The Japanese version of the SF-36v2 ${ }^{\mathrm{TM}}$ has been validated for Japanese subjects aged 15 years or older. ${ }^{42}$

\section{Neuropsychological assessment}

A battery of neuropsychological tests was administered to all subjects to assess the relationship between cognitive dysfunction and suicidality. The neuropsychological tests administered in this study and their cognitive domains were as follows: Wisconsin Card Sorting Test (WCST), executive function; Auditory Verbal Learning Test (AVLT), verbal learning and memory; Word Fluency Test (WFT), verbal fluency; Trail Making Test (TMT), visual-motor processing and motor speed; Stroop Test, response inhibition and selective attention. For the WCST, the computerized Japanese Keio University version was used. The category of achievement (CA) and two types of perseverative errors (Nelson and Milner) were assessed. The TMT had two parts. In part A (TMT-A), the subjects were required to draw lines to connect the circles numbered 1-25 in ascending order. In part B (TMT-B), the subjects were required to draw lines to connect between the circles numbered 1-13 and 12 hiragana (Japanese syllabary order) alternately in ascending order. In the AVLT, the subjects were required to learn a ten item word list over four trials (trials 1-4) and were then assessed 30 minutes later (trial 5). The number of recall words in trial 1 was used as an indication of the immediate recall. The result of trial 5 indicated delayed recall. This battery was described in our previous study. ${ }^{43}$

\section{Statistical analysis}

Descriptive statistics were provided regarding demographic data and were subjected to an analysis of variance (ANOVA), the Fisher's exact tests, and the Kruskal-Wallis test. For analyses of self-assessment scales and neuropsychological assessment data, ANOVA and Tukey's honest significant difference (HSD) test as post hoc analyses were applied.

A significance level of $P<0.05$ was selected for the ANOVA, Fisher's exact test, and Kruskal-Wallis test. Bonferroni's correction was not applied because of the small sample size. All data were analyzed using SPSS version 21.0 (IBM Corporation, Armonk, NY, USA).

\section{Results \\ Demographic data}

Demographic data are presented in Table 1. The mean age and the ratio of female to male subjects between three groups were not significantly different. The medical history of psychiatry, the family history of psychiatric illness, and the family history of suicide were not significantly different. The rate of psychiatric comorbidities in the MDEs with suicide risk group was significantly higher than that in the MDEs without

Table I Demographic data

\begin{tabular}{|c|c|c|c|}
\hline & HCs & $\begin{array}{l}\text { MDEs without } \\
\text { suicidal risk }\end{array}$ & $\begin{array}{l}\text { MDEs with } \\
\text { suicidal risk }\end{array}$ \\
\hline$N$ & 15 & 15 & 15 \\
\hline $\begin{array}{l}\text { Age, mean } \pm \text { standard } \\
\text { deviation }^{\mathrm{a}}\end{array}$ & $20.9 \pm 1.9$ & $21.7 \pm 2.4$ & $22.3 \pm 3.3$ \\
\hline Sex, female/male ${ }^{b}$ & $5 / 10$ & $4 / 11$ & $7 / 8$ \\
\hline $\begin{array}{l}\text { Medical history of } \\
\text { psychiatric disorders }^{\mathrm{b}}\end{array}$ & 0 & 2 & 2 \\
\hline $\begin{array}{l}\text { Family history of } \\
\text { psychiatric disorders }^{\mathrm{b}}\end{array}$ & 0 & 0 & 3 \\
\hline Family history of suicide ${ }^{b}$ & 0 & I & I \\
\hline History of suicide attempt $\mathrm{t}^{\mathrm{b}}$ & 0 & I & 1 \\
\hline \multicolumn{4}{|l|}{ Comorbidity ${ }^{c, *}$} \\
\hline $\mathrm{PD}$ & 0 & I & 2 \\
\hline SAD & 0 & 2 & 3 \\
\hline GAD & 0 & 0 & 2 \\
\hline $\mathrm{BN}$ & 0 & I & I \\
\hline \multicolumn{4}{|l|}{ BDI-II, \#9, Suicidality,* } \\
\hline 0 & 13 & 6 & 0 \\
\hline I & 2 & 9 & 9 \\
\hline 2 & 0 & 0 & 4 \\
\hline 3 & 0 & 0 & 2 \\
\hline
\end{tabular}

Notes: ${ }^{a} \mathrm{ANOVA}$, ns; ' Fisher's exact test, ns; 'Fisher's exact test, $P<0.05$; 'KruskalWallis test, $P<0.01$. *Statistically significant. \#9 refers to suicidal thoughts. Abbreviations: $\mathrm{HC}$, healthy control; MDE, major depressive episode group; PD, panic disorder; SAD, social anxiety disorder; GAD, generalized anxiety disorder; BN, bulimia nervosa; BDI-II, Beck Depression Inventory, edition two; ns, not significant. 
Table 2 Comparison of depressive symptoms, psychological assessment score, neuropsychological test score and SF-36v2 score by ANOVA

\begin{tabular}{|c|c|c|c|c|c|c|c|c|}
\hline & \multirow{2}{*}{$\begin{array}{l}\text { HCs (I) } \\
\overline{\text { Mean (SD) }}\end{array}$} & \multirow{2}{*}{$\begin{array}{l}\text { MDEs without } \\
\text { suicide risk (2) } \\
\text { Mean (SD) }\end{array}$} & \multirow{2}{*}{$\begin{array}{l}\text { MDEs with } \\
\text { suicide risk (3) } \\
\text { Mean (SD) }\end{array}$} & \multirow[t]{2}{*}{$\boldsymbol{F}$} & \multirow[t]{2}{*}{$P$-value } & \multicolumn{3}{|c|}{ Tukey's HSD test } \\
\hline & & & & & & (I) vs (3) & (I) vs (2) & (2) vs (3) \\
\hline BDI-II & $7.1(5.7)$ & $29.5(7.0)$ & $32.6(8.0)$ & 68.2 & $<0.001$ & $<0.001$ & $<0.001$ & ns \\
\hline $\mathrm{BHS}$ & 7.1 (4.7) & $14(3.3)$ & I4.4 (4.0) & 15.3 & $<0.001$ & $<0.001$ & $<0.001$ & ns \\
\hline RSES & $34.5(7.8)$ & $24.8(6.9)$ & $19.9(5.4)$ & 19.7 & $<0.001$ & $<0.001$ & 0.001 & $<0.05$ \\
\hline JART50 & I07.I (5.5) & I09.3 (4.9) & II $2.7(5.0)$ & 3.7 & $<0.05$ & $<0.05$ & ns & ns \\
\hline WCST, CA & $5.8(0.4)$ & $5.5(0.5)$ & $5.9(0.4)$ & 2.5 & ns & & & \\
\hline AVLT, IR & $5.6(I . I)$ & $6.0(1.2)$ & $5.8(1.7)$ & 0.6 & ns & & & \\
\hline AVLT, DR & 8.1 (I.2) & $7.8(1.6)$ & $8.5(1.5)$ & 0.5 & ns & & & \\
\hline Stroop & $4.6(2.7)$ & $4.5(3.4)$ & $5.5(4.0)$ & 0.5 & ns & & & \\
\hline TMT, A & $54.8(10.4)$ & $64.6(8.4)$ & $61.2(18.2)$ & 3.5 & $<0.05$ & ns & $<0.05$ & ns \\
\hline TMT, B & $58.9(11.3)$ & $73.0(16.4)$ & $63.8(20.4)$ & 3.7 & $<0.05$ & ns & $<0.05$ & ns \\
\hline WFT & $29.1(6.9)$ & $30.8(10.3)$ & $32.8(13.9)$ & 0.6 & ns & & & \\
\hline \multicolumn{9}{|l|}{ SF-36v2 } \\
\hline PF & $57.3(1.9)$ & $50.2(7.3)$ & $49.5(8.0)$ & 7.0 & $<0.01$ & $<0.01$ & $<0.05$ & ns \\
\hline $\mathrm{RP}$ & $45.5(9.1)$ & $31.6(18.5)$ & $31.6(17.6)$ & 4.7 & 0.001 & $<0.05$ & $<0.05$ & ns \\
\hline $\mathrm{BP}$ & $47.8(9.0)$ & $49.1(10.5)$ & $47.3(10.8)$ & 0.0 & ns & & & \\
\hline $\mathrm{GH}$ & $53.1(7.4)$ & $43.6(4.1)$ & $43.4(5.5)$ & 13.3 & $<0.001$ & $<0.001$ & $<0.001$ & ns \\
\hline VT & $48.5(8.4)$ & 30.1 (5.I) & $29.1(7.2)$ & 36.6 & $<0.001$ & $<0.001$ & $<0.001$ & ns \\
\hline SF & $50.6(11.0)$ & $34.1(12.4)$ & $27.6(11.0)$ & 20.6 & $<0.001$ & $<0.001$ & $<0.001$ & $<0.05$ \\
\hline RE & $42.7(15.3)$ & $16.3(6.3)$ & $16.0(9.7)$ & 31.0 & $<0.001$ & $<0.001$ & $<0.001$ & ns \\
\hline $\mathrm{MH}$ & 49.1 (8.4) & $29.8(4.2)$ & $25.5(7.2)$ & 49.5 & $<0.001$ & $<0.001$ & $<0.001$ & ns \\
\hline
\end{tabular}

Abbreviations: HC, healthy controls; MDE, major depressive episode; BDI-II, Beck Depression Inventory, edition two; BHS, Beck Hopelessness Scale; RSES, Rosenberg's Self-Esteem Scale; JART, Japanese Adult Reading Test; WCST, Wisconsin Card Sorting Test; CA, category achievement; AVLT, Auditory Verbal Learning Test; IR, immediate recall; DR, delayed recall; TMT, Trail Making Test; WFT, Word Fluency Test; SF-36v2, Medical Outcomes Study 36-item short-form health survey version 2; PF, physical functioning; RP, role physical; BP, bodily pain; GH, general health; VT, vitality; SF, social functioning; RE, role emotional; MH, mental health; ANOVA, analysis of variance; HSD, honest significant difference; SD, standard deviation; vs, versus; ns, not significant.

suicide risk group (Fisher's exact test, $P<0.05$ ). Moreover, we confirmed that the distribution of the scores on the BDI for the ninth item, which assessed suicidal thoughts, was significantly different among the healthy controls, the MDEs with suicide risk group, and the MDEs without suicide risk group (Kruskal-Wallis test, $P<0.001$ ).

\section{Self-report data}

The results of self-assessment scale scores are presented in Table 2. The mean BDI-II scores, BHS scores, and RSES scores were compared among the three groups (Table 2). The results of ANOVA revealed significant effects on BDI-II scores $(\mathrm{F}[2,42]=68.2, P<0.001)$, BHS scores $(\mathrm{F}[2,42]=15.3$, $P<0.001)$, and RSES scores $(\mathrm{F}[2,42]=19.7, P<0.001)$. A post hoc analysis using the Tukey's HSD test was performed. Although both the MDEs with suicide risk group and the MDEs without suicide risk group had significantly higher BDI-II scores $(P<0.001)$ and BHS scores $(P<0.001)$ than did the healthy controls, no significant difference was found between the MDEs without suicide risk group and the MDEs with suicide risk group. The RSES score of the MDEs with suicide risk group was significantly lower than the scores for the healthy controls $(P<0.001)$ and the MDEs without suicide risk group $(P<0.05)$, which was lower than that of the healthy controls.

The mean SF-36v2 subscale scores, except BP, were significantly lower in the MDEs with and without suicide risk groups than in the healthy controls. Only the mean social functioning score in the SF-36v2 of the MDEs with suicide risk group was significantly lower than that of the MDEs without suicide risk group $(P<0.05)$.

\section{Cognitive functions}

The mean TMT-A score and TMT-B score were significantly higher (ie, worse) in the MDEs without suicide risk group than in healthy controls. However, no significant differences in the means of the TMT-A and TMT-B scores were observed between the MDEs with suicide risk group and healthy controls. Furthermore, no significant differences were observed in the WCST CA scores, AVLT scores, Stroop scores, or WFT scores between healthy controls, the MDEs without suicide risk group, and the MDEs with suicide risk group.

\section{Discussion}

The main finding of the present study was that the MDEs of MDD with suicide risk group had lower self-esteem than the 
MDEs of MDD without suicide risk group, and each group had the same degree of severity of depression. Rosenberg described self-esteem as a global concept of the self and a sense of worth or value, but not as possession or accumulation of specific qualities or abilities. ${ }^{38}$ Low self-esteem implies self-rejection, self-dissatisfaction, and self-contempt. ${ }^{38}$ In a previous study, self-esteem was negatively associated with suicidal ideation after controlling for depression and hopelessness in psychiatric outpatients. ${ }^{44}$ Moreover, a negative relationship was found between the level of suicidality and self-esteem in university undergraduates. ${ }^{45}$ It is not surprising that individuals who lack respect for themselves would have suicidal ideation tendencies.

The deterioration in mean social functioning scores was found in MDE of MDD patients with suicide risk in the present study. The low social functioning score indicates extreme and frequent interference with normal social activities due to physical and emotional problems. Normal social activities require good relationships with others, such as colleagues, friends, and family. Previous studies reported poorer quality of life in MDD patients compared with controls. ${ }^{46}$ Suicidal ideation was also reportedly correlated with low quality of life, specifically with respect to $\mathrm{BP}{ }^{47}$ However, the association between suicide risk and low social functioning scores on the SF-36v2 has not been previously reported.

In our previous study, we reported that immature character profiles with low self-directedness and/or low cooperativeness on the TCI would have a strong impact on the prevalence of depressive episodes and ideas of suicide or self-harm among young adult populations. ${ }^{28}$ Self-esteem and the ability to accept one's limitations are crucial aspects of the development of mature self-directedness. In addition, cooperative individuals are described as socially tolerant, empathic, helpful, and compassionate. ${ }^{48}$ Taken together, the association of low selfesteem and low social functioning with suicide risk appears to be consistent with and supportive of the results of our previous study. ${ }^{28}$

One of the limitations of this study was the small sample size ( $n=15$ per group), as a small sample size decreases the statistical power. The main reason for this small sample size was the difficulty with administering the neuropsychological battery to large numbers of moderate to severe unmedicated depressive patients. The observational, cross-sectional study design was another limitation of this study, as it does not allow us to evaluate the outcome of suicide risk.

In conclusion, self-esteem and social functioning may play important roles in suicide risk of young adult unmedicated patients with MDEs of MDD.

\section{Acknowledgments}

This study was partly supported by the program "Integrated research on neuropsychiatric disorders" and conducted under the Strategic Research Program for Brain Sciences by the Ministry of Education, Culture, Sports, Science, and Technology of Japan; a Research Grant 24-2 for Nervous and Mental Disorders from the Ministry of Health, Labor and Welfare; and a grant from the Interdisciplinary Project for Psychosomatological Research at Hokkaido University.

\section{Disclosure}

Dr $\mathrm{T}$ Inoue has received honoraria from GlaxoSmithKline, Pfizer, Astellas, Eli Lilly, Mitsubishi Tanabe Pharma, Mochida Pharmaceutical, Otsuka Pharmaceutical, Meiji Seika Pharma, Asahi Kasei Pharma, Shionogi, Janssen Pharmaceutical, Takeda Pharmaceutical and Yoshitomi Pharmaceutical, has received research/grant support from Otsuka Pharmaceutical, and is a member of the advisory boards of GlaxoSmithKline, Eli Lilly, Mochida Pharmaceutical and Mitsubishi Tanabe Pharma. Dr I Kusumi has received honoraria from Eli Lilly and has received research/grant support from Takeda Pharmaceutical, Astellas and Dainippon Sumitomo Pharma, and is a member of the advisory board of Dainippon Sumitomo Pharma and Tanabe Mitsubishi Pharma. Dr T Tanaka has received honoraria from GlaxoSmithKline, Otsuka Pharmaceutical, Eli Lilly, Meiji Seika Pharma, Yoshitomi Pharmaceutical. Other authors have no potential conflicts of interests in this work.

\section{References}

1. Desapriya EB, Iwase N. New trends in suicide in Japan. Inj Prev. 2003;9(3):284.

2. Hawton K, van Heeringen K. Suicide. Lancet. 2009;373(9672): 1372-1381.

3. Mann JJ, Waternaux C, Haas GL, Malone KM. Toward a clinical model of suicidal behavior in psychiatric patients. Am J Psychiatry. 1999;156(2):181-189.

4. Paris J. Predicting and preventing suicide: do we know enough to do either? Harv Rev Psychiatry. 2006;14(5):233-240.

5. Beghi M, Rosenbaum JF, Cerri C, Cornaggia CM. Risk factors for fatal and nonfatal repetition of suicide attempts: a literature review. Neuropsychiatr Dis Treat. 2013;9:1725-1736.

6. Cash SJ, Bridge JA. Epidemiology of youth suicide and suicidal behavior. Curr Opin Pediatr. 2009;21(5):613-619.

7. Rihmer Z. Suicide risk in mood disorders. Curr Opin Psychiatry. 2007;20(1):17-22.

8. Lepine JP, Briley M. The increasing burden of depression. Neuropsychiatr Dis Treat. 2011;7(Suppl 1):3-7.

9. Wulsin LR, Vaillant GE, Wells VE. A systematic review of the mortality of depression. Psychosom Med. 1999;61(1):6-17.

10. McMillan D, Gilbody S, Beresford E, Neilly L. Can we predict suicide and non-fatal self-harm with the Beck Hopelessness Scale? A metaanalysis. Psychol Med. 2007;37(6):769-778.

11. Patsiokas AT, Clum GA, Luscomb RL. Cognitive characteristics of suicide attempters. J Consult Clin Psychol. 1979;47(3):478-484. 
12. Raust A, Slama F, Mathieu F, et al. Prefrontal cortex dysfunction in patients with suicidal behavior. Psychol Med. 2007;37(3):411-419.

13. Keilp JG, Sackeim HA, Brodsky BS, Oquendo MA, Malone KM, Mann JJ. Neuropsychological dysfunction in depressed suicide attempters. Am J Psychiatry. 2001;158(5):735-741.

14. Marzuk PM, Hartwell N, Leon AC, Portera L. Executive functioning in depressed patients with suicidal ideation. Acta Psychiatr Scand. 2005;112(4):294-301.

15. Overholser JC, Adams DM, Lehnert KL, Brinkman DC. Self-esteem deficits and suicidal tendencies among adolescents. J Am Acad Child Adolesc Psychiatry. 1995;34(7):919-928.

16. Kelly TM, Lynch KG, Donovan JE, Clark DB. Alcohol use disorders and risk factor interactions for adolescent suicidal ideation and attempts. Suicide Life Threat Behav. 2001;31(2):181-193.

17. Goldney RD, Smith S, Winefield AH, Tiggeman M, Winefield HR. Suicidal ideation: its enduring nature and associated morbidity. Acta Psychiatr Scand. 1991;83(2):115-120.

18. McGee R, Williams S. Does low self-esteem predict health compromising behaviours among adolescents? J Adolesc. 2000;23(5):569-582.

19. Lewinsohn PM, Rohde P, Seeley JR. Psychosocial risk factors for future adolescent suicide attempts. J Consult Clin Psychol. 1994;62(2):297-305.

20. Kjelsberg E, Neegaard E, Dahl AA. Suicide in adolescent psychiatric inpatients: incidence and predictive factors. Acta Psychiatr Scand. 1994;89(4):235-241.

21. Wilburn VR, Smith DE. Stress, self-esteem, and suicidal ideation in late adolescents. Adolescence. 2005;40(157):33-45.

22. Creemers DH, Scholte RH, Engels RC, Prinstein MJ, Wiers RW. Implicit and explicit self-esteem as concurrent predictors of suicidal ideation, depressive symptoms, and loneliness. J Behav Ther Exp Psychiatry. 2012;43(1):638-646.

23. Manani P SS. Self esteem and suicidal ideation: a correlational study. MIER Journal of Educational Studies, Trends and Practices. 2013;3: $75-83$.

24. Koivumaa-Honkanen H, Honkanen R, Viinamaki H, Heikkila K, Kaprio J, Koskenvuo M. Life satisfaction and suicide: a 20-year follow-up study. Am J Psychiatry. 2001;158(3):433-439.

25. Berlim MT, Mattevi BS, Pavanello DP, Caldieraro MA, Fleck MP. Suicidal ideation and quality of life among adult Brazilian outpatients with depressive disorders. J Nerv Ment Dis. 2003;191(3):193-197.

26. Brezo J, Paris J, Turecki G. Personality traits as correlates of suicidal ideation, suicide attempts, and suicide completions: a systematic review. Acta Psychiatr Scand. 2006;113(3):180-206.

27. Mitsui N, Asakura S, Inoue T, et al. Temperament and character profiles of Japanese university student suicide completers. Compr Psychiatry. 2013;54(5):556-561.

28. Mitsui N, Asakura S, Shimizu Y, et al. Temperament and character profiles of Japanese university students with depressive episodes and ideas of suicide or self-harm: A PHQ-9 screening study. Compr Psychiatry. 2013;54(8):1215-1221.

29. Chamberlain SR, Odlaug BL, Schreiber LR, Grant JE. Clinical and neurocognitive markers of suicidality in young adults. J Psychiatr Res. 2013;47(5):586-591.

30. Sheehan DV, Lecrubier Y, Sheehan KH, et al. The Mini-International Neuropsychiatric Interview (MINI): the development and validation of a structured diagnostic psychiatric interview for DSM-IV and ICD-10. J Clin Psychiatry. 1998;59 Suppl 20:22-33;quiz 34-57.
31. Otsubo T, Tanaka K, Koda R, et al. Reliability and validity of Japanese version of the Mini-International Neuropsychiatric Interview. Psychiatry Clin Neurosci. 2005;59(5):517-526.

32. Beck AT, Steer RA, Ball R, Ranieri W. Comparison of Beck Depression Inventories -IA and -II in psychiatric outpatients. $J$ Pers Assess. 1996;67(3):588-597.

33. Steer RA, Clark DA. Psychometric characteristics of the Beck Depression Inventory-II with college students. Meas Eval Couns Dev.1997;30(3):128-129.

34. Kojima M, Furukawa TA, Takahashi H, Kawai M, Nagaya T, Tokudome S. Cross-cultural validation of the Beck Depression Inventory-II in Japan. Psychiatry Res. 2002;110(3):291-299.

35. Beck AT, Weissman A, Lester D, Trexler L. The measurement of pessimism: the hopelessness scale. J Consult Clin Psychol. 1974; 42(6):861-865.

36. Beck AT, Brown G, Berchick RJ, Stewart BL, Steer RA. Relationship between hopelessness and ultimate suicide: a replication with psychiatric outpatients. Am J Psychiatry. 1990;147(2):190-195.

37. Tanaka E, Sakamoto S, Ono Y, Fujihara S, Kitamura T. Hopelessness in a community population in Japan. J Clin Psychol. 1996;52(6): 609-615.

38. Rosenberg M. Society and the Adolescent Self-Image. Princeton, N.J: Princeton University Press; 1965.

39. Robins RW, Hendin HH, Trzesniewski KH. Measuring global selfesteem: Construct validation of a single-item measure and the Rosenberg self-esteem scale. Pers Soc Psychol Bull. 2001;27(2):151-161.

40. Yamamoto M MY, Yamanari Y. The structure of perceived aspects of Self. Jpn J of Educ Psychol. 1982;30:64-68.

41. Ware JE Jr, Sherbourne CD. The MOS 36-item short-form health survey (SF-36). I. Conceptual framework and item selection. Med Care. 1992;30(6):473-483.

42. Fukuhara S, Bito S, Green J, Hsiao A, Kurokawa K. Translation, adaptation, and validation of the SF-36 Health Survey for use in Japan. J Clin Epidemiol. 1998;51(11):1037-1044.

43. Toyomaki A, Kusumi I, Matsuyama T, Kako Y, Ito K, Koyama T. Tone duration mismatch negativity deficits predict impairment of executive function in schizophrenia. Prog Neuropsychopharmacol Biol Psychiatry. 2008;32(1):95-99.

44. Bhar S, Ghahramanlou-Holloway M, Brown G, Beck AT. Self-esteem and suicide ideation in psychiatric outpatients. Suicide Life Threat Behav. 2008;38(5):511-516.

45. Thompson AH. The suicidal process and self-esteem. Crisis. 2010;31(6):311-316.

46. Papakostas GI, Petersen T, Mahal Y, Mischoulon D, Nierenberg AA, Fava M. Quality of life assessments in major depressive disorder: a review of the literature. Gen Hosp Psychiatry. 2004;26(1): 13-17.

47. Gensichen J, Teising A, Konig J, Gerlach FM, Petersen JJ. Predictors of suicidal ideation in depressive primary care patients. $J$ Affect Disord. 2010;125(1-3):124-127.

48. Cloninger CR, Svrakic DM, Przybeck TR. A psychobiological model of temperament and character. Arch Gen Psychiatry. 1993;50(12): 975-990.
Neuropsychiatric Disease and Treatment

\section{Publish your work in this journal}

Neuropsychiatric Disease and Treatment is an international, peerreviewed journal of clinical therapeutics and pharmacology focusing on concise rapid reporting of clinical or pre-clinical studies on a range of neuropsychiatric and neurological disorders. This journal is indexed on PubMed Central, the 'PsycINFO' database and CAS.
Dovepress

The manuscript management system is completely online and includes a very quick and fair peer-review system, which is all easy to use. Visit http://www.dovepress.com/testimonials.php to read real quotes from published authors. 